\title{
Stock Investment of Agriculture Companies in the Vietnam Stock Exchange Market: An AHP Integrated with GRA-TOPSIS-MOORA Approaches*
}

\author{
Phi-Hung NGUYEN ${ }^{1}$, Jung-Fa TSAI ${ }^{2}$, Venkata Ajay KUMAR G ${ }^{3}$, Yi-Chung HU ${ }^{4}$
}

Received: May 02, 2020 Revised: May 17, 2020 Accepted: June 07, 2020

\begin{abstract}
Multi-criteria stock selection is a critical issue for effective investment since the improper stock investment might cause many problems affecting investors negatively. Investors need a range of financial indicators while they are choosing the optimal set of stocks to invest. This study aims to rank the stock of agriculture companies indexed on the Vietnam Stock Exchange Market. The data of 13 agriculture companies during the 2016-2019 periods was analyzed by analytical hierarchy process (AHP) integrated with grey relational analysis (GRA), multiobjective optimization ratio analysis (MOORA), and technique for order performance by similarity to ideal solution (TOPSIS). The AHP method is employed to determine the weights of the proposed financial ratios, and GRA, TOPSIS, and MOORA approaches are used to obtain final ranking. The results indicated that HSL is the top stock with the highest rank and GRA, MOORA, and TOPSIS rankings have strong correlation values between 0.78 -1. The findings suggest that the integrated model could be implemented effectively to specific analysis of industries such as oil and gas, textiles, food, and electronics in future research. Further, other techniques like COPRAS, KEMIRA, and EDAS could be employed to evaluate the financial performance of other companies to solve investment problems.
\end{abstract}

Keywords: AHP, GRA, TOPSIS, MOORA, Stock Investment, Vietnam.

JEL Classification Code: C02, C61, D53, Q14

\section{Introduction}

\footnotetext{
*Acknowledgment:

The authors would like to thank the anonymous referees for constructive comments on the earlier version of this paper.

${ }^{1}$ First Author and Corresponding Author. [1] Department of Business Management, National Taipei University of Technology, Taipei 10608, Taiwan; [2] Faculty of Business, FPT University, Hanoi, Vietnam [Postal Address: Hoa Lac High-Tech Park, Km29, Thang Long Boulevard, Hanoi, 100000, Vietnam]

Email: hungnp30@fe.edu.vn

${ }^{2}$ Department of Business Management, National Taipei University of Technology, Taipei 10608, Taiwan, Email: jftsai@ntut.edu.tw ${ }^{3}$ Department of Mechanical Engineering, Annamacharya Institute of Technology \& Sciences, New Boyanapalle, Rajampet - 516126, Andhrapradesh, India, Email: ajay.ajay79@gmail.com

${ }^{4}$ Department of Business Administration, Chung Yuan Christian University, Taoyuan City, 32023, Taiwan, Email: ychu@cycu.edu.tw

(c) Copyright: The Author(s)

This is an Open Access article distributed under the terms of the Creative Commons Attribution Non-Commercial License (http://Creativecommons.org/licenses/by-nc/4.0/) which permits unrestricted noncommercial use, distribution, and reproduction in any medium, provided the original work is properly cited.
}

In today's competitive world economy, the agriculture sector is one of the key players in almost all developed and developing countries. The stock market leads financial resources for achieving the goals of the economy. It contributes to national food security, economic growth. Investors are considering the agriculture industry as the best place for investment to increase their portfolio and income. However, numerous variables, such as exchange rate and inflation rate, have a dynamic relationship with stock prices in both long-run and short-run causality (Lee \& Brahmasrene, 2018, 2019). The stock selection represents a challenging task in determining the factors influencing the investors' decisions. Evaluating the financial performance of a company has attracted enormous attention, and interest from various parties such as managers, creditors, financial experts, current/ potential investors, researchers. The modeling of financial problems is more complicated and is sometimes conflicting, not to mention the subjectivity of the decision-makers in the evaluation process. Multi-criteria decision making (MCDM) methods have been used systematically as a tool to aid in financial decision-making (Zopounidis \& Doumpos, 2002). 
Especially, the application of MCDM in financial decisions has increased dramatically with the number of publications since 2002 (Zavadskas et al., 2004). The financial ratios are usually derived from the balance sheet, income statement, and cash flow. They are considered as crucial measurement tools in determining the performance and financial assets of companies. Apart from the financial ratios, the integrated approach of decision-making applied to machine process experimental run selection also by integrating AHP with VIKOR and WASPAS (Kumar et al ., 2018).

Many studies have shown that financial ratios data are useful as well (Chen \& Shimerda, 1981; Singh \& Schmidgall, 2002). Nguyen and Nguyen (2020) investigated the determinant of the financial ratios categorized into six industries listed on the Vietnam Stock Exchange from 2014 to 2017. They revealed that the agriculture sector accounted for the highest percentage of profitability. Ertuğrul and Karakaşoğlu (2009) analyzed a fuzzy model based on FAHP and TOPSIS (Technique for Order Preference by Similarity to Ideal Solution) methods to evaluate the performance of the Turkish cement firms by using financial ratios. Wu and $\mathrm{Yu}$ (2011) developed the VIKOR method focusing on the ranking of alternatives. Yalcin et al. (2012) studied a new financial performance evaluation using an integrated TOPSIS and VIKOR. They indicated that the ranks of alternatives are almost the same in their sectors. Özdağoğlu et al. (2017) approached GRA to investigate all manufacturing industry companies and employed a significant number of ratios for Grey analysis. Sharma et al. (2018) proposed Rating Transition Matrices (RTM) to investigate rating trends and forecast rating movements through the application of rating transition matrices. They found that general insurers reflect less stable rating outlooks compared to life and general insurers. Raju and Rao (2019) compared AHM, CAMEL, and Grey Relation analysis to get the Grey coefficient, and then Data Envelop Analysis is applied to obtain ranks of nationalized banks. Aldalou and Percin (2020) combined Fuzzy Shannon's Entropy (FSE) method and Fuzzy EDAS (FEDAS) method to evaluate and rank alternatives.

In this paper, an integrated approach of AHP, GRA, TOPSIS, MOORA methods has been utilized. This study proposes a model to evaluate the financial performance of 13 agriculture companies to select the best stock, listed on the Vietnamese Stock Exchange Market between the period of 2016-2019. During the assessment procedure, AHP is used to determine the weights of the financial ratios, whereas the GRA, TOPSIS, and MOORA method are conducted for ranking alternatives in this case study. With the proposed method, the evaluation problem of financial performance can be easily solved, and Spearman's rank correlation test is implemented to verify that there is no significant difference between the GRA, TOPSIS, and MOORA rankings and differentiated from previous studies in the literature. After the introduction section, this study is organized as follows: Section 2 briefly explained the selected financial ratios to avoid repeated with alternative researches. In Section 3, MCDM approaches of AHP, GRA, TOPSIS, and MOORA are summarized. An empirical example is discussed. Section 4 concludes the paper presenting our findings, and insights for future studies are clarified.

\section{Financial Ratios}

Based on financial statements, there are about 20 meaningful financial ratios, and they are separated into several categories because experts suppose that financial ratios are partially similar in the same one category (Jain \& Dubes, 1988). Investors usually analyze stock market ratios, efficiency ratios, profitability ratios, liquidity ratios, and leverage ratios. Large quantities of financial data can make the problem more complicated.

In this study, 13 most traded stocks of agriculture companies from the Vietnamese Stock Exchange Market have been considered, in the period from December 2016 to December 2019. The data was obtained from the VietStock database (https://vietstock.vn/) and taken as average values. These agriculture stocks are APC, ASM, HAG, HNG, HSL, NSC, SJF, SSC, CTP, HKT, PMB, PSW, and VIF. The selected financial indicators are Price earning per share ratio $(\mathrm{P} / \mathrm{E})$, Market to book ratio(P/B), Return on assets( ROA); Profit margin on sales( PMS), Quick ratio( QR) and Total debt ratio(DTR). The significant financial ratios as selected criteria in the evaluation process of stock investment were defined in Table 1.

\section{MCDM Methods}

MCDM is a subdiscipline branch of operational research in order to support the subjective evaluation of a set of decision alternatives under a finite number of performance criteria (Lootsma, 1999). Numerous MCDM methods are employed for various case studies; different techniques may obtain different consequences for the identical issue. The proposed procedure in this study is used to select the best stock of 13 Vietnamese agriculture companies, as summarized in Figure1.

\subsection{AHP}

AHP was suggested by (Saaty, 2000; White, 1987) to analyze various MCDM problems. This method is applied to determine the weights of hierarchical level criteria. The steps of AHP is presented as follows:

Step 1: Creating the Hierarchical Structure: The goal of the study and criteria suitable for the criteria are determined and then the alternatives. 
Table 1: Proposed Financial Ratios

\begin{tabular}{|c|c|c|}
\hline Financial ratio & Formulas & Proposed quality of ratios \\
\hline $\begin{array}{c}\text { Price/earnings ratio } \\
\text { (P/E) }\end{array}$ & $\begin{array}{c}\text { Market price per share } \\
\text { Earning per share }\end{array}$ & Lower is better \\
\hline $\begin{array}{c}\text { Market/book ratio } \\
\text { (P/B) }\end{array}$ & $\begin{array}{c}\text { Market price per share } \\
\text { Book value per share }\end{array}$ & Hower is better \\
\hline $\begin{array}{c}\text { Return on total assets } \\
\text { (ROA) }\end{array}$ & $\begin{array}{c}\text { Net income after taxes } \\
\text { Total assets }\end{array}$ & Higher is better \\
\hline $\begin{array}{c}\text { Profit margin on sales } \\
\text { (PMS) }\end{array}$ & $\begin{array}{c}\text { Net income after taxes } \\
\text { Sales }\end{array}$ & Higher is better \\
\hline $\begin{array}{c}\text { Quick ratio } \\
(\mathrm{QR})\end{array}$ & $\begin{array}{c}\text { Current assets-Inventories } \\
\text { Total liabilities }\end{array}$ & Lower is better \\
\hline $\begin{array}{c}\text { Total debt ratio } \\
\text { (TDR) }\end{array}$ & $\begin{array}{c}\text { Total liabilities } \\
\text { Total asset }\end{array}$ & \\
\hline
\end{tabular}

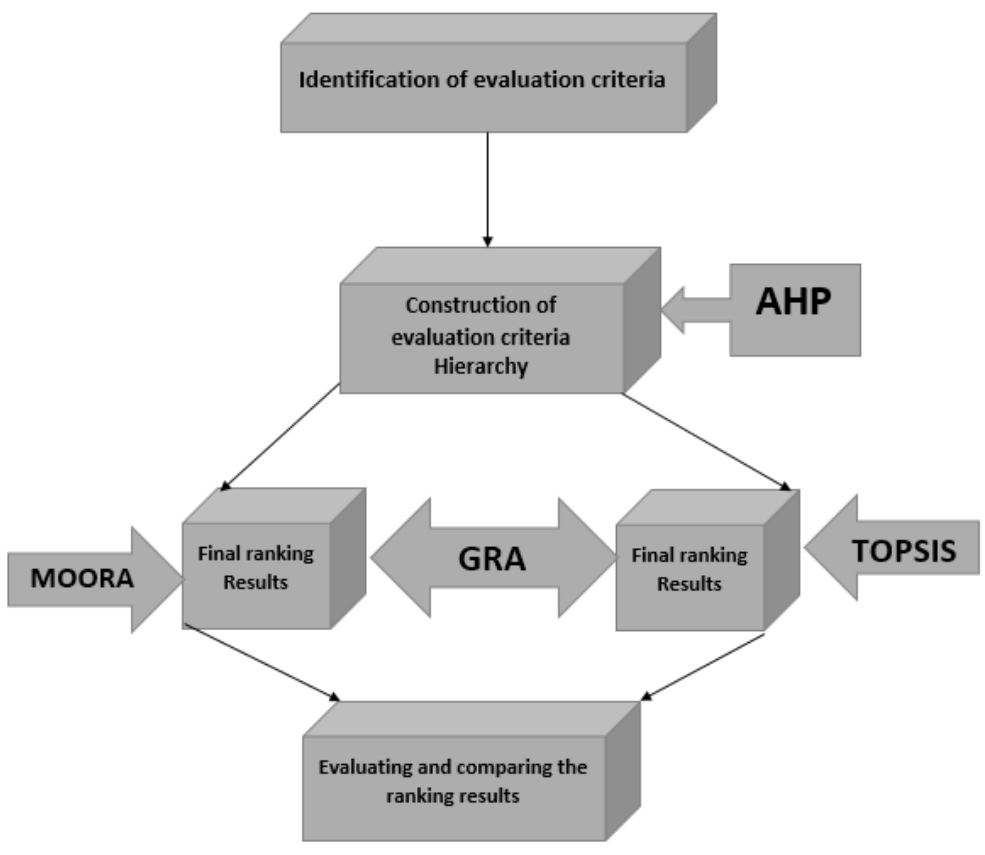

Figure 1: The Proposed Methodology

Step 2: Constructing the pairwise comparison Matrices and Superiority. The importance scales proposed by (White, 1987) are used to prepare the matrix.

$$
A=\left[\begin{array}{cccc}
1 & a_{21} & \cdots & a_{n 1} \\
\frac{1}{a_{31}} & 1 & \cdots & a_{n 2} \\
\frac{1}{a_{31}} & \frac{1}{a_{32}} & \cdots & a_{n 3} \\
\vdots & \vdots & \ddots & \vdots \\
\frac{1}{a_{n 1}} & \frac{1}{a_{n 2}} & \cdots & 1
\end{array}\right]_{n x n}
$$

Step 3: Determining of normalized decision matrix and constructing the weights of alternatives.

$$
\begin{aligned}
& c_{i j}=\frac{a_{i j}}{\sum_{J=1}^{n} a_{i j}} \\
& i=1,2,3, \ldots . ., j=1,2,3, \ldots n \\
& w_{i}=\sum_{J=1}^{n} \frac{C_{i j}}{n} \quad i=1,2,3, \ldots, n
\end{aligned}
$$




$$
W=\left[\begin{array}{c}
w_{1} \\
w_{2} \\
\cdot \\
\cdot \\
w_{n}
\end{array}\right]
$$

Step 4: Calculation of Matrix Consistency: The Consistency Ratio (CR) formula introduced by Saaty is used in measuring the consistency, and it is expected to be smaller than 0.10 .

RI values can be calculated for up to 15-dimensional matrixes.

$$
\text { Consistency Ratio }=\frac{\text { Consistency Index }(C I)}{\text { Random Index }(R I)}
$$

Calculation of CI is given in Equation (5)

$$
C I=\frac{\lambda_{\max }-n}{n-1}
$$

If $\mathrm{CR}>0.10$, it is accepted that the comparison matrix is inconsistent. In this situation, the comparison matrix is revisited, and the necessary arrangements are made for its consistency (Saricali and Kudakci, 2016).

\subsection{GRA}

Grey system theory was introduced by (Deng J, 1989). GRA is a technique of grey theory for analyzing the relationship between a reference series and other series. It consists of three steps normalization of the decision matrix, estimation of grey relational coefficientfollowed by estimation of grey relational grade (GRG) eventually ranking the best alternative based on the highest value of GRG.

The normalization of the decision matrix using Eq. (6) \& Eq. (7)

For lower-the-better attributes

$$
Z_{i j}=\frac{z_{i j}^{\max }-z_{i j}}{z_{j}^{\max }-z_{j}^{\min }}
$$

For higher-the-better attributes

$$
Z_{i j}=\frac{z_{i j}-z_{i j}^{\min }}{z_{j}^{\max }-z_{j}^{\min }}
$$

The second step is used to obtain the grey relational coefficient (GRC), which shows the relationship between ideal and normalized data, estimated by using Eq. (8)

$$
\xi_{i}(k)=\frac{\Delta_{\min }+\zeta \Delta_{\max }}{\Delta_{o i}(k)+\zeta \Delta_{\max }}
$$

Where $\Delta_{o i}(k)=\left\|Z_{0}^{*}(k)-Z_{i}^{*}(k)\right\|, \quad Z_{0}^{*}(k)$ represents the reference sequence and $Z_{i}^{*}(k)$ represents the comparability sequence. $\Delta_{\min }$ And $\Delta_{\max }$ are the minimum and maximum values if.$\Delta_{o i}(k)$. The distinguished coefficient $\zeta$ varied from 0 to 1 , here for the solving $\zeta$ considered as 0.5 .

Grey relational Grade (GRG) is estimated by averaging the GRC with weight for all the attributes by using Eq. (9).

$$
\gamma_{i}=\frac{1}{n} \sum_{k=1}^{n} \omega_{k} \xi_{i}(k)
$$

Where $\omega_{k}$ represents the weight criteria, calculated by using the AHP method. Consequently, the financial performance of agriculture companies can be ranked according to GRG. The higher GRG shows a better stock.

\subsection{TOPSIS}

TOPSIS method was developed byHwang and Yoon (1981). TOPSIS obtains the best selection by attempting to indicate that the best alternative is the closest to the ideal solution. In other words, the best alternative has the most distant solution from the anti-ideal solution. The procedure for implementing TOPSIS is presented as follows:

Step 1: Constructing the normalized decision matrix of beneficial and non-beneficial criteria using the Eq. (10).

$$
R_{i j}=\frac{m_{i j}}{\sqrt{\sum_{j=1}^{M} m_{i j}^{2}}}
$$

Step 2: Constructing the weighted normalized decision matrix by multiplying the weights wi of evaluation with criteria with the normalized decision matrix $\mathrm{r}_{\mathrm{ij}}$ Eq. (11).

$$
V_{i j}=w_{j} R_{i j}
$$

Step 3: Determining the positive ideal solution and negative ideal solution using Eq. (12). 


$$
\begin{aligned}
& A^{+}=\left\{V_{i j}^{+} 1, \ldots \ldots . V_{n}^{+}\right\}=\left\{\left(\max V_{i j} \mid i \in I^{\prime}\right),\left(\min V_{i j} \mid i \in I_{I}^{\prime \prime}\right)\right. \\
& A^{-}=\left\{V_{i j} 1, \ldots \ldots . V_{n}^{-}\right\}=\left\{\left(\max V_{i j} \mid i \in I^{\prime}\right),\left(\min V_{i j} \mid i \in_{I}^{\prime \prime}\right)\right.
\end{aligned}
$$

Step 4: Calculation of the separation measure of each alternative with Eq.(13) and Eq. (14)

$$
\begin{aligned}
& D_{j}^{+}=\sqrt{\sum_{i=1}^{n}\left(v_{i j}-v_{j}^{+}\right)^{2}} \\
& D_{j}^{-}=\sqrt{\sum_{i=1}^{n}\left(v_{i j}-v_{j}^{-}\right)^{2}}
\end{aligned}
$$

Step 5: Computing the relative closeness to the ideal solution ( $\mathrm{CCi}$ )

$$
C_{c i}=\frac{D_{j}^{-}}{D_{j}^{+}+D_{j}^{-}}
$$

Step 6: Ranking the preference order according to the descending order of $\left(\mathrm{C}_{\mathrm{Ci}}\right)$. The alternative having the highest closeness coefficient $\left(\mathrm{C}_{\mathrm{Ci}}\right)$ is selected based on the decreasing values of the closeness coefficient, alternatives are ranked from most valuable to worst.

\subsection{MOORA}

The MOORA method, introduced to the academic world byBrauers and Zavadskas (2006), is such a multi-objective optimization technique that can be successfully applied to solve various types ofcomplex decision- making problems under certain constraints.

Step 1: Starting with a decision matrix

Step 2: Developing a ratio system for all the alternatives concerning that attribute. The equation is used for matrix normalization is shown as follows with Eq. (16)

$$
\begin{aligned}
& x_{i j}^{*}=\frac{X_{i j}}{\sqrt{\sum_{i=1}^{m} X_{i j}^{2}}} \\
& \mathrm{i}=1,2, \ldots, \mathrm{m} \text { and } \mathrm{j}=1,2, \ldots, \mathrm{n}
\end{aligned}
$$

Step 3: Normalized goal values in the table are determined as maximum or minimum and aggregated among themselves. The collected minimum goal values are subtracted from the collected maximum goal values with its corresponding weights by Eq. (17).

$$
y_{i}=\sum_{j=1}^{g} w_{j} x_{i j}^{*}-\sum_{j=g+1}^{n} w_{j} x_{i j}^{*}(j=1,2, \ldots, n)
$$

The $y_{i}$ value can be positive or negative depending on the totals of its maxima (beneficial attributes) and minima (non-beneficial attributes) in the decision matrix. The best alternative has the highest $\mathrm{y}_{\mathrm{i}}$ value, while the worst alternative has the lowest $y_{i}$ value.

\section{Results and Discussions}

\subsection{Criteria Weighting by Using AHP}

The criteria compared pairwise based on the experience of the financial advisors. A pairwise comparison matrix complied based on the financial ratios considered for this problem.Here, PMS, ROA, and $\mathrm{QR}$ are the beneficial attributes (higher the better) followed by $\mathrm{P} / \mathrm{E}, \mathrm{P} / \mathrm{B}$, and TDR are non-beneficial attributes (means for smaller the better). The determination of subjective weights for the corresponding attributes are

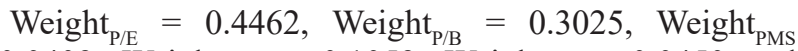
$=0.0409$, Weight $_{\mathrm{ROA}}=0.1059$, Weight $_{\mathrm{QR}}=0.0450$ and Weight $_{\mathrm{TDR}}=0.0596$.

The weights are finalized from the pairwise comparison matrix of the AHP, where the CI $=0.023503$ and $\mathrm{CR}=$ 0.018954 , which is less than 0.01 and reflects the judgment of the decision-maker is apt.

\subsection{Grey Relational Analysis Integrated with AHP}

For the ranking of the stock, the GRA method is employed first. The decision matrix for the stocks given in Table 2, it is normalized based on the lower-the-better and higher-thebetter using the Eq. (6) \& Eq. (7).

Further, the deviation sequence estimated and using Eq. (8) grey relation coefficient evaluated. The weights obtained from AHP used for evaluating the grey relational grade, based on the grade values the ranking of the stocks (alternatives) by $\mathrm{GRA}$ is $\mathrm{HSL}>\mathrm{APC}>\mathrm{CTP}>\mathrm{VIF}>\mathrm{HNG}>\mathrm{PMB}>\mathrm{ASM}$ $>\mathrm{SJF}>\mathrm{PSW}>\mathrm{NSC}>\mathrm{HAG}>\mathrm{SSC}>\mathrm{HKT}($ see Table 3 ).

\subsection{TOPSIS Integrated with AHP}

Using Eq. (10) the decision matrix was normalized, and the weights from the AHP method used to tabulate the 
Table 2: Decision-Making Matrix

\begin{tabular}{|c|c|c|c|c|c|c|}
\hline Alternatives & P/E & $\mathrm{P} / \mathrm{B}$ & PMS & ROA & QR & TDR \\
\hline (1) APC & 7.31 & 1.52 & 66.58 & 17.94 & 3.52 & 17.77 \\
\hline (2) ASM & 9.49 & 0.68 & 14.51 & 5.92 & 1.55 & 51.71 \\
\hline (3) HAG & 37.45 & 0.28 & 26.62 & -0.34 & 0.71 & 64.12 \\
\hline (4) HNG & -4.7 & 1.02 & 24.93 & -3.18 & 0.68 & 65.55 \\
\hline (5) HSL & 1.98 & 0.38 & 11.19 & 18.62 & 267.79 & 3.02 \\
\hline (6) NSC & 7.59 & 1.44 & 36.52 & 13.19 & 1.98 & 29.64 \\
\hline (7) SJF & 18.49 & 0.57 & 36.52 & 3.46 & 1.81 & 29.64 \\
\hline (8) SSC & 12.38 & 2.27 & 29.34 & 15.14 & 3.52 & 24.03 \\
\hline (9) CTP & 7.5 & 0.67 & 8.91 & 7.33 & 6.25 & 17.16 \\
\hline (10) HKT & 133.33 & 0.18 & 11 & 2.49 & 2.97 & 22.5 \\
\hline (11) PMB & 7.44 & 0.75 & 5.06 & 7.99 & 4.57 & 20.22 \\
\hline (12) PSW & 13.68 & 0.76 & 2.92 & 4.62 & 3.85 & 25.52 \\
\hline (13) VIF & 6.32 & 0.86 & 14.16 & 10.84 & 5.63 & 13.69 \\
\hline
\end{tabular}

Table 3: Grey Relational Coefficient, Grade and Ranking of Alternatives

\begin{tabular}{|c|c|c|c|c|c|c|c|c|}
\hline \multirow{2}{*}{ Alternatives } & \multicolumn{6}{|c|}{ Grey Relational Coefficient - GRC } & \multirow{2}{*}{ Grade } & \multirow{2}{*}{ Rank } \\
\hline & $P / E$ & P/B & PMS & ROA & $Q R$ & TDR & & \\
\hline 1 & 0.85177 & 0.43816 & 1.00000 & 0.94128 & 0.33571 & 0.67945 & 0.11812 & 2 \\
\hline 2 & 0.82946 & 0.67638 & 0.37938 & 0.46186 & 0.33406 & 0.39103 & 0.11290 & 7 \\
\hline 3 & 0.62083 & 0.91266 & 0.44338 & 0.36504 & 0.33336 & 0.33849 & 0.10751 & 11 \\
\hline 4 & 1.00000 & 0.55438 & 0.43318 & 0.33333 & 0.33333 & 0.33333 & 0.11695 & 5 \\
\hline 5 & 0.91175 & 0.83936 & 0.36494 & 1.00000 & 1.00000 & 1.00000 & 0.14768 & 1 \\
\hline 6 & 0.84884 & 0.45336 & 0.51430 & 0.66748 & 0.33442 & 0.54012 & 0.10913 & 10 \\
\hline 7 & 0.74850 & 0.72822 & 0.51430 & 0.41827 & 0.33428 & 0.54012 & 0.11113 & 8 \\
\hline 8 & 0.80161 & 0.33333 & 0.46084 & 0.75800 & 0.33571 & 0.59809 & 0.10139 & 12 \\
\hline 9 & 0.84978 & 0.68078 & 0.35564 & 0.49121 & 0.33803 & 0.68858 & 0.11798 & 3 \\
\hline 10 & 0.33333 & 1.00000 & 0.36415 & 0.40326 & 0.33525 & 0.61612 & 0.09344 & 13 \\
\hline 11 & 0.85041 & 0.64706 & 0.34097 & 0.50627 & 0.33660 & 0.64510 & 0.11605 & 6 \\
\hline 12 & 0.78969 & 0.64308 & 0.33333 & 0.43775 & 0.33599 & 0.58151 & 0.10944 & 9 \\
\hline 13 & 0.86231 & 0.60580 & 0.37780 & 0.58351 & 0.33750 & 0.74556 & 0.11747 & 4 \\
\hline
\end{tabular}

weighted normalized matrix with the Eq. (11). The positive and negative (ideal) solutions from Eq.(12) are represented in Table 4.

The separation matrix $D_{j}^{+}$and $D_{j}^{-}$from the Eq. 13 and Eq. 14 calculated based on the separation matrix, the closeness value $C_{C i}$ estimated by using Eq. 15. Finally, the stocks (alternatives) are ranked in the Table 5 as HSL $>$ CTP $>\mathrm{VIF}>\mathrm{PMB}>\mathrm{ASM}>\mathrm{HNG}>\mathrm{PSW}>\mathrm{SJF}>\mathrm{NSC}>\mathrm{APC}$ $>\mathrm{HAG}>\mathrm{SSC}>\mathrm{HKT}($ see Table 5$)$.

\subsection{MOORA Integrated with AHP}

The decision matrix considered from Table 2, Eq. (16) is applied for the normalization. The overall assessment value $\left(\mathrm{y}_{\mathrm{i}}\right)$ is estimated by using Eq. (17) and the weights used here are estimated by using AHP; the ranking of alternatives are also shown in Table 6. The ranking of the stocks (alternatives) from MOORA are $\mathrm{HSL}>\mathrm{VIF}>\mathrm{CTP}>\mathrm{PMB}>\mathrm{APC}>\mathrm{ASM}$ $>\mathrm{SJF}>\mathrm{HNG}>\mathrm{PSW}>\mathrm{NSC}>\mathrm{HAG}>\mathrm{SSC}>\mathrm{HKT}$. 
Table 4: Ideal Positive and Negative Solutions

\begin{tabular}{|l|c|c|c|c|c|c|}
\hline & P/E & P/B & PMS & ROA & QR & TDR \\
\hline Ideal P & -0.01474 & 0.014581 & 0.027125 & 0.052846 & 0.044932 & 0.001432 \\
\hline Ideal N & 0.418129 & 0.183886 & 0.00119 & -0.00903 & 0.000114 & 0.031079 \\
\hline
\end{tabular}

Table 5: Distance of Ideal Positive and Negative, Relative Closeness Coefficient and Ranking

\begin{tabular}{|c|c|c|c|c|}
\hline Alternatives & Positive & Negative & Relative & Rank \\
\hline 1 & 0.123371 & 0.40578 & 0.76685 & 10 \\
\hline 2 & 0.088874 & 0.410064 & 0.82187 & 11 \\
\hline 3 & 0.153448 & 0.341404 & 0.68991 & 6 \\
\hline 4 & 0.10786 & 0.444645 & 0.80478 & 1 \\
\hline 5 & 0.034793 & 0.447041 & 0.92779 & 9 \\
\hline 6 & 0.120164 & 0.403299 & 0.77044 & 8 \\
\hline 7 & 0.102173 & 0.386653 & 0.79098 & 12 \\
\hline 8 & 0.184191 & 0.383509 & 0.67555 & 2 \\
\hline 9 & 0.081171 & 0.417059 & 0.83708 & 13 \\
\hline 10 & 0.438228 & 0.171321 & 0.28106 & 4 \\
\hline 11 & 0.08448 & 0.415324 & 0.83097 & 7 \\
\hline
\end{tabular}

Table 6: Weighted Normalized Decision Matrix and Ranking

\begin{tabular}{|c|c|c|c|c|c|c|c|c|}
\hline Alternatives & P/E & P/B & PMS & ROA & QR & TDR & Yi & Rank \\
\hline 1 & 0.05138 & 0.40699 & 0.66374 & 0.48091 & 0.01313 & 0.14142 & -0.07585 & 5 \\
\hline 2 & 0.06670 & 0.18207 & 0.14465 & 0.15869 & 0.00578 & 0.41152 & -0.08639 & 6 \\
\hline 3 & 0.26323 & 0.07497 & 0.26538 & -0.00911 & 0.00265 & 0.51028 & -0.16053 & 11 \\
\hline 4 & -0.03304 & 0.27311 & 0.24853 & -0.08524 & 0.00254 & 0.52166 & -0.09772 & 8 \\
\hline 5 & 0.01392 & 0.10175 & 0.11155 & 0.49914 & 0.99895 & 0.02403 & 0.063913 & 1 \\
\hline 6 & 0.05335 & 0.38557 & 0.36407 & 0.35358 & 0.00739 & 0.23588 & -0.10186 & 10 \\
\hline 7 & 0.12997 & 0.15262 & 0.36407 & 0.09275 & 0.00675 & 0.23588 & -0.09321 & 7 \\
\hline 8 & 0.08702 & 0.60780 & 0.29249 & 0.40585 & 0.01313 & 0.19123 & -0.17859 & 12 \\
\hline 9 & 0.05272 & 0.17940 & 0.08882 & 0.19649 & 0.02331 & 0.13656 & -0.06045 & 3 \\
\hline 10 & 0.93717 & 0.04820 & 0.10966 & 0.06675 & 0.01108 & 0.17906 & -0.43133 & 13 \\
\hline 11 & 0.05230 & 0.20082 & 0.05044 & 0.21418 & 0.01705 & 0.16091 & -0.06817 & 4 \\
\hline 12 & 0.09616 & 0.20349 & 0.02911 & 0.12385 & 0.01436 & 0.20309 & -0.10162 & 9 \\
\hline 13 & 0.04442 & 0.23027 & 0.14116 & 0.29058 & 0.02100 & 0.10895 & -0.0585 & 2 \\
\hline
\end{tabular}




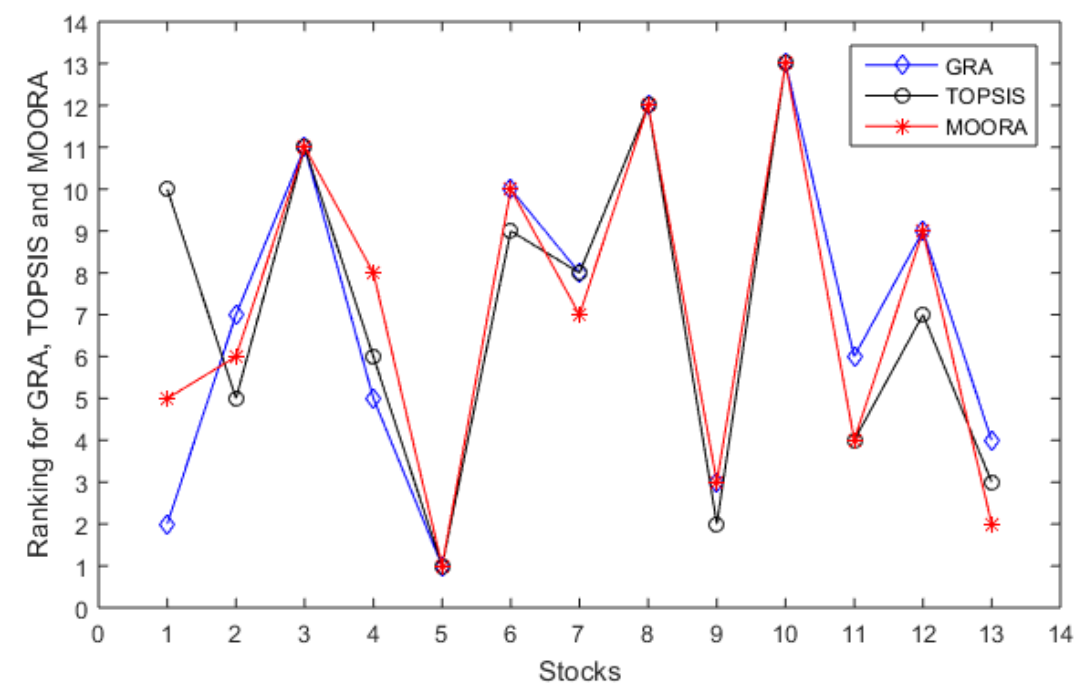

Figure 2: Comparison of Ranking Methods

\subsection{Comparison of Ranking Methods}

From the three ranking methods, HSL outperformed the others utilizing better ROA, QR, and TDR. In this study, HSL is the best alternative, and HKT is the worst alternative for all three ranking methods shown in Figure 2. Spearman rank coefficient (correlation) for the three methods applied and shown in the table. It is evident that the Spearman correlation coefficient for GRA and MOORA has 0.92307, which is close to 1 , between TOPSIS and MOORA has 0.8956 and between GRA and TOPSIS has 0.78022 , shows ranks are in perfect and also have a strong correlation. However, the correlation values between $0.78-1$.

\section{Conclusion}

The fuzzy environmental criteria in the process of stock selection are attaining more importance day by day. Financial ratios provide useful quantitative financial information to both investors and analysts, so that they can evaluate a company. In this study, the integrated method based onAHP, GRA, TOPSIS, and MOORA successfully determined the ranking of the stocks in the Vietnamese agriculture sector by comparing the companies according to the determined criteria of financial ratios. This research could be applied to specific analysis of industries such as oil and gas, textiles, food, and electronics, in order to assert the validity of the results. Future research may deal with a greater number of criteria values with different weight calculation methodsunder the fuzzy business environment such as Fuzzy AHP and Fuzzy Entropy to increase the power of varying stock portfolios.
Further, other techniques like COPRAS, KEMIRA, and EDAS could be used to evaluate the financial performance of other companies to solve investment problems.

\section{References}

Aldalou, E., \&Perçin, S. (2020). Fuzzy CCMM approach in Financial Performance Evaluation of Food and Beverage Index. International Journal of Economics and Innovation, (March), 1-19. https://doi.org/10.20979/ueyd.650422

Brauers, W. K. M., \& Zavadskas, E. K. (2006). The MOORA method and its application to privatization in a transition economy. Control and Cybernetics, 35(2), 445-469.

Chen, K. H., \& Shimerda, T. A. (1981). An Empirical Analysis of Useful Financial Ratios. Financial Management, 10(1), 51. https://doi.org/10.2307/3665113

Deng J. (1989). Introduction to grey system. Journal of Grey System, 1(1), 1-24.

Ertuğrul, I., \& Karakaşoğlu, N. (2009). Performance evaluation of Turkish cement firms with fuzzy analytic hierarchy process and TOPSIS methods. Expert Systems with Applications, 36(1), 702-715. https://doi.org/10.1016/j.eswa.2007.10.014

Hwang, C.-L., \& Yoon, K. (1981). Multiple criteria decision making. Lecture Notes in Economics and Mathematical Systems, 186, 58-191.

Jain, A. K., \& Dubes, R. C. (1988). Algorithms for Clustering Data. Englewood Cliffs, New Jersey: Prentice-Hall.

Kumar, V. A., Reddy, D. V. V., \& Nagaraju, N. (2018). MultiObjective Optimization of End Milling Process Parameters in Machining of En 31 Steel: Application of Ahp Embedded With Vikor and Waspas Methods. I-Manager's Journal on 
Mechanical Engineering, 8(4), 39. https://doi.org/10.26634/ jme.8.4.14676

Lee, J. W., \& Brahmasrene, T. (2018). An exploration of dynamical relationships between macroeconomic variables and stock prices in Korea. Journal of Asian Finance, Economics and Business, 5(3), 7-17. https://doi.org/10.13106/jafeb.2018. vol5.no3.7

Lee, J. W., \& Brahmasrene, T. (2019). Long-run and shortrun causality from exchange rates to the Korea composite stock price index. Journal of Asian Finance, Economics and Business, 6(2), 257-267. https://doi.org/10.13106/jafeb.2019. vol6.no2.257

Lootsma, F. A. (1999). Multi-Criteria Decision Analysis via Ratio and Difference Judgement. In Multi-Criteria Decision Analysis via Ratio and Difference Judgement (Vol. 29). https://doi. org/10.1007/b102374

Nguyen, T. N. L., \& Nguyen, V. C. (2020). The determinants of profitability in listed enterprises: A study from vietnamese stock exchange. Journal of Asian Finance, Economics and Business, 7(1), 47-58. https://doi.org/10.13106/jafeb.2020. vol7.no1.47

Özdağoğlu, A., Gümüş, Y., Özdağoğlu, G., \& Gümüş, G. K. (2017). Evaluating Financial Performance With Grey Relational Analysis: An Application Of Manufacturing Companies Listed On Borsa İstanbul. Muhasebe ve Finansman Dergisi, (73), 289312. https://doi.org/10.25095/mufad.396758

Raju, V. K. V., \& Rao, V. V. S. K. (2019). Financial performance ranking of nationalized banks through integrated AHM-GRADEA method. International Journal of Management, 10(3), 1535. https://doi.org/10.34218/IJM.10.3.2019/003

Saaty, T. L. (2000). Fundementals of decision making and priority theory. In Pittsburgh, PA: RWS Publications (Vol. 21). RWS publications.
Sariçali, G., \&Kundakci, N. (2016). The evaluation of hotel alternatives with the AHP and COPRAS methods.International Review of Economics and Management, 4(1), 45-66.

Sharma, A., Jadi, D. M., \& Ward, D. (2018). Evaluating financial performance of insurance companies using rating transition matrices. Journal of Economic Asymmetries, 18. https://doi. org/10.1016/j.jeca.2018.e00102

Singh, A. J., \& Schmidgall, R. S. (2002). Analysis of financial ratios commonly used by US lodging financial executives. Journal of Retail \& Leisure Property, 2(3), 201-213. https:// doi.org/10.1057/palgrave.rlp.5090210

White, G. P. (1987). The implementation of management science in higher education administration. Omega, 15(4), 283-290. https://doi.org/10.1016/0305-0483(87)90016-8

Yalcin, N., Bayrakdaroglu, A., \& Kahraman, C. (2012). Application of fuzzy multi-criteria decision making methods for financial performance evaluation of Turkish manufacturing industries. Expert Systems with Applications, 39(1), 350-364. https://doi. org/10.1016/j.eswa.2011.07.024

Wu, Y.-Y., \& Yu, D.-J. (2011). Extended VIKOR for multi-criteria decision making problems under intuitionistic environment. International Conference on Management Science and Engineering - Annual Conference Proceedings, 118-122. https://doi.org/10.1109/ICMSE.2011.6069952

Zavadskas, E. K., Ustinovichius, L., \& Stasiulionis, A. (2004). Multicriteria valuation of commercial construction projects for investment purposes. Journal of Civil Engineering and Management, 10(2), 151-166. https://doi.org/10.1080/139237 30.2004 .9636299

Zopounidis, C., \& Doumpos, M. (2002). Multi-criteria decision aid in financial decision making: Methodologies and literature review. Journal of Multi-Criteria Decision Analysis, 11(4-5), 167-186. https://doi.org/10.1002/mcda.333 